\title{
FEATURES OF ACCOUNTING SEARCH ASSETS IN THE EXPLORATION OF PLATINOIDS
}

\author{
(C) 2020 Shatunova Galina Aleksandrovna \\ Candidate of Economic Sciences, Professor \\ (C) 2020 Arkhipova Natalia Anatolevna \\ Candidate of Economic Sciences, associate Professor \\ Samara state University of Economics \\ E-mail: shatunova.ga@yandex.ru
}

Keywords: search costs, search assets, tangible search assets, intangible search assets, search assets depreciation.

The article deals with the issues of formation of expenses for evaluation and exploration of mineral deposits in the accounting and reporting of companies engaged in the extraction of platinum group metals. An approach is proposed to reflect the impairment of search assets recognized in the process of evaluation and exploration of mineral deposits in the accounting accounts. Proposals for amendments to the current standard PBU 24/2011 "Accounting for the development of natural resources", aimed at eliminating inconsistencies with the current accounting practice of PJSC MMC Norilsk Nickel, which produces solid minerals.

УДК 339

Код РИНЦ 06.00.00

\section{ЭЛЕКТРОННАЯ КОММЕРЦИЯ: МИРОВЫЕ И РОССИЙСКИЕ ТЕНДЕНЦИИ РАЗВИТИЯ РЫНКА РОЗНИЧНОЙ ТОРГОВЛИ}

\author{
(ㄱ) 2020 Шведова Ксения Сергеевна* \\ студент \\ Самарский государственный экономический университет \\ E-mail: ksenya.shvedova@mail.ru
}

Ключевые слова: электронная коммерция, розничная торговля, российский рынок розничной торговли, мировой рынок розничной торговли, интернет-магазины, потребители.

В данной статье рассматривается рынок электронной (онлайн) коммерции как часть рынка розничной торговли и дальнейшие пути его развития. Выделяются общие черты мировой тенденции (дигитализации) и самые крупные и влиятельные рынки электронной коммерции. Целью исследования является выявление тех тенденций, которые выступают современными инструментами при развитии бизнеса торговых предприятий. Для достижения поставленной цели необходимо решить следующие задачи: раскрыть сущность понятия электронная коммерция, проанализировать динамику мирового рынка электронной коммерции, выявить ключевые тенденции развития электронной коммерции в дальнейшем.

* Научный руководитель - Курникова Марина Викторовна, кандидат экономических наук, доцент. 
Цифровизация является одной из наиболее значительных трансформаций современного общества и охватывает многие элементы бизнеса и повседневной жизни. В сфрере розничной торговли цифровизация предопределяет возникновение цифровых экосистем и инновационных бизнес-моделей. Ритейлеры предоставляют потребителям различные цифровые продукты и услуги, которые адаптированы киспользованию в условиях цифровизации.

С возникновением Сети Интернет рынок розничной торговли претерпел существенные изменения, которые повлияли на бизнес-модели, формы торговли, процессы закупок и т.д. За последние несколько лет предприятия во всем мире испытали значительные изменения в своей информационной системе ведения бизнеса. Для создания качественно нового направления в бизнес-индустрии были вложены огромные инвестиции в процесс модификации и перехода к использованию инновационных технологий (создание приложений, облачные хранения, использование интернет сети). Для того, чтобы конкурировать компаниям, как на внутренних, так и на внешних рынках были созданы такие нововведения, как: электронный бизнес, электронные продажи, электронные закупки, электронная доставка, электронные платежи, е-CRM, e-CAD, электронный банкинг. Фактически, предпосылкой существования электронной коммерции является интернет.

Электронная коммерция определяется как способность осуществлять транзакции, связанные с обменом товарами и/или услугами между двумя или несколькими сторонами с применением информационных технологий на основе сетевых взаимодействий ${ }^{1}$. Появление интернет торговли способствовало модернизации сервиса и взаимосвязи между покупателем и продавцом. Интеграция цифровых технологий в розничную торговлю означает трансформацию ранее существовавших действий, процессов, товаров, продуктов, услуг.

В целом, необходимо подчеркнуть, что на глобальном рынке розничной торговли происходит существенное ужесточение конкурентной борьбы, в том числе со стороны виртуальных компаний, консолидации рынка, а также ряда банкротств крупных компаний отрасли. Проводятся масштабные сокращения в рамках реструктуризации и оптимизации деятельности многих мировых компаний, таких как Amazon (США) и Carrefour (Франция).

За последние годы по объему продаж в сфрере интернет-торговли лидирует Китай, годовой доход которого превысил \$600 млрд в 2018 году. Второе место с доходом в $\$ 475$ млрд занимает США. Далее со значительным отставанием следуют Япония - \$105 млрд, Великобритания - \$103 млрд, Германия - \$57 млрд В таких странах, как Китай и Южная Корея онлайн покупатели наиболее активны. 83\% составляет удельный вес вовлеченного в онлайн покупки населения в Китае, в Великобритании данный показатель составляет $82 \%$, в Германии - 81\%, в Индонезии удельный вес равен 79\%, в США - 77\%, в Индии $77 \%$.

2018 год был одним из самых тяжелых для сектора розничной торговли - ритейлеры столкнулись со снижением потребительских расходов, изменению вкусов покупателей и быстрым ростом онлайн-продаж. Это привело к массовому закрытию магазинов - более 9 000 в одних только США - и уменьшению прибыли.

Несмотря на эти проблемы, крупнейшие в мире ритейлеры остаются одними из компаний с наибольшим оборотом в мире, и недавний отчет Института реального роста (IRG), опубликованный Kantar / WPP, подчеркивает огромные масштабы этих предприятий. 
Десять крупнейших мировых компаний розничной торговли в 2018 году

\begin{tabular}{|c|c|c|c|c|}
\hline № & $\begin{array}{l}\text { Название } \\
\text { компании }\end{array}$ & $\begin{array}{c}\text { Страна } \\
\text { происхожде- } \\
\text { ния }\end{array}$ & $\begin{array}{c}\text { Выручка, 2018г. (млрд } \\
\text { дол. США) }\end{array}$ & $\begin{array}{c}\text { Совокупный } \\
\text { среднегодовой темп } \\
\text { роста, \% } \\
(2018 / 2017)\end{array}$ \\
\hline 1 & WalMart Stores, Inc. & США & 517 & $4 \%$ \\
\hline 2 & Amazon & США & 213 & $6 \%$ \\
\hline 3 & $\begin{array}{l}\text { Costco Wholesale } \\
\text { Corporation }\end{array}$ & США & 144 & $1,7 \%$ \\
\hline 4 & Schwarz Group & Германия & 130 & $7,3 \%$ \\
\hline 5 & Kroger Co. & США & 124 & $1,2 \%$ \\
\hline 6 & $\begin{array}{l}\text { Walgreens Boots } \\
\text { Alliance, Inc }\end{array}$ & США & 114 & $17,6 \%$ \\
\hline 7 & The Home Depot, Inc. & США & 109 & $6,1 \%$ \\
\hline 8 & Aldi Group & Германия & 108 & $7,7 \%$ \\
\hline 9 & Carrefour S.A. & Франция & 101 & $-1,1 \%$ \\
\hline 10 & JD.Com & Китай & 94 & $6,4 \%$ \\
\hline
\end{tabular}

Источник: Digital Economy Compass 2018 [Электронный ресурc]. URL: http://static2.statista.com/ download/pdf/Digital_Economy_Compass_2018. Pdf.

В топ-5 крупнейших компаний розничной торговли в мире вошли такие компании как WalMart Stores (США), Amazon.com (США), Costco Wholesale Corporation (США), Schwarz Group (Германия), Kroger Co. (США) ${ }^{3}$.

Пятерка крупнейших компаний лидеров сохранила свои позиции в списке прошлого года. Компания Amazon является наиболее инвестиционно привлекательной, вследствие того, что она по-прежнему наращивает темпы роста (19\% в 2018 году), а также имеет едва ли не самую низкую рентабельность по EBITDA среди компаний технологического сектора. Необходимо отметить, что по показателям ожидаемого роста прибыли за акцию Amazon является лидером.

Компании Amazon, Wal-Mart Stores, The Home Depot также входят в пятерку электронных розничных продавцов США по годовому объему продаж нетто-электронной торговли в 2017 году.

По данным стратегии Painting the digital future of retail and consumer goods companies основными технологиями, которые играют ключевую роль в развитии мировой электронной коммерции до 2025 года, являются:4

- Интернет вещей (Internet of Things)

- Автономные транспортные средства/ Дроны (Autonomous Vehicles/Drones)

- Искусственный интеллект (Artificial Intelligence)

- Робототехника Robotics

- Цифровое отслеживание (Digital Traceability)

- 3D Печать (3D Printing)

- Виртуальная реальность (Virtual Reality)

- Блокчейн (Blockchain) 
Компании, которые смогут использовать данные технологии станут лидерами в списке крупнейших компаний розничной торговли в мире уже ближе к 2026 году.

Авторами вышеупомянутой стратегии были выделены четыре бизнес-модели, формирующие будущее электронной коммерции:

1. Экономика совместного потребления (аренда товара для определенного случая с последующим его возвратом)

2. Экономика персонализации (ориентация на конкретного покупателя, повышение его лояльности путем создания персонифицированных акций)

3. Экономика автоматического пополнения (использование интеллектуальных датчиков для автоматического пополнения товара)

4. Экономика сервиса (использование услуг подрядчиков)

Несмотря на стремительный рост цифровой торговли, физический магазин по-прежнему остается крупнейшим каналом сбыта продукции, приносящим доход. По мере развития интернет-магазинов и неуклонного роста онлайн-продаж розничные продавцы будут сокращать общее количество физических магазинов, что в скором будущем приведет к их полному исчезновению.

В России рынок электронной торговли также стремительно растет. Уступив США, Китаю и Великобритании, Россия вышла на четвертое место в мире по темпам роста и объему электронной торговли в 2018 году. Общий объем инвестиций в российскую электронную торговлю в 2018 году составил 756 млн долл. по данным международного информационного агентства East-West Digital News. Из всех отраслей наибольший рост показал сегмент электронной коммерции, который по сравнению с прошлым годом увеличился на 16\%. В табл. 2 приведен список из десяти крупнейших компаний розничной торговли в России.

Таблица 2

Десять крупнейших российских компаний розничной торговли в 2018 году

\begin{tabular}{|c|l|c|c|}
\hline № & \multicolumn{1}{|c|}{ Название компании } & $\begin{array}{c}\text { Выручка, 2018г. (млрд } \\
\text { руб.) }\end{array}$ & $\begin{array}{c}\text { Совокупный среднего- } \\
\text { довой темп роста, \% } \\
\text { (2018/2017) }\end{array}$ \\
\hline 1 & $\begin{array}{l}\text { X5 Retail Group ("Пятерочка", "Пере- } \\
\text { кресток", "Карусель") }\end{array}$ & 1532,5 & 18,3 \\
\hline 2 & "Магнит" & 1237 & 8,2 \\
\hline 3 & "Лента" & 413,5 & 13,2 \\
\hline 4 & "М.Видео-Эльдорадо" & 321,2 & 62,1 \\
\hline 5 & Auchan & 306,4 & $-8,5$ \\
\hline 6 & "SPS Холдинг" ("Красное \& белое") & 301 & 40 \\
\hline 7 & ГК "Дикси" & 298,7 & 5,6 \\
\hline 8 & Leroy Merlin & 272 & 20,7 \\
\hline 9 & DNS & 268,5 & 35,7 \\
\hline 10 & Metro & 203,3 & -8 \\
\hline
\end{tabular}

Источник: Аналитический обзор "Российский FMCG-ритейл в 2018 г. и прогноз на 2019-2024 гг." [Электронный ресурс]. URL: https://ma-research.ru/research/item/223-rossijskij-fmcg-ritejl-v-2018-g-iprognoz-na-2019-2024-gg.html 
Оборот первой в списке компании X5 Retail Group ("Перекресток", "Пятерочка", "Карусель") увеличился на 18,3\%, до 1,53 трлн руб. (без НДС) в 2018 году. Второе место занимает компания "Магнит", выручка которой за тот же период выросла на 8,2\%, до 1,23 трлн руб. На третьем месте, как и в 2017 году компания "Лента", выручка которой выросла на 13,2\%, до 413,5 млрд руб в 2018 году 5.

Отечественная онлайн розница за последние несколько лет росла бурными темпами (\$2,17 млрд оборот в 2018 г., прирост составил 15\%). На сегодняшний день, успешно конкурируя с зарубежными аналогами за российского покупателя, отечественные компании пытаются выходить на международные рынки. Так, по обороту интернет торговлиРоссия находилась на 8 месте в мире и на 4 в Европе по итогам 2017 года.

В число крупнейших магазинов электронной коммерции России входят: Aliexpress (212 млрд руб.), Wildberries (120 млрд руб.), Citilink (77,4 млрд руб.), Ozon (42,5 млрд руб.), Ulmart (30 млрд руб.) по данным 2018 года.

Исследования в сфрере е-соmmerce непосредственно свидетельствуют о том, что цифровые технологии могут создавать и направлять весь путь, который проходит покупатель от знакомства с товаром вплоть до его приобретения. Подобные технологические процессы создают новейшие схемы взаимодействия с покупателем. Применяя их, можно управлять коммуникациями, увеличить продажи, повысить прибыльность компании и приобрести преимущества в конкурентной борьбе.

В основу стратегии развития лидеров рынка положеныб:

- автоматизация бизнес-процессов;

- комплексная маркетинговая стратегия, основанная на возможности оплаты товаров наиболее удобным для покупателя способом;

- применение моделей оценки эффрективности коммуникаций

- организация служб логистики

- гармонизация ассортимента и программ лояльности;

- создание баз данных о потребителях с целью прогнозирования потребностей покупателей и персонификации предложений.

Таким образом, для электронной коммерции характерно: использование моделей продвижения, ориентация на определенно покупателя, повышение его доверия путем создания персональных акций, формирование личного кабинета покупателя, адресных предложений. Ключевым показателем предприятия, использующего цифровые технологии, является гибкость. Компании - лидеры совершенствуют это качество, используя цифровые технологии для удовлетворения быстро меняющихся потребностей рынка по всему миру.

Электронная коммерция является ключевым драйвером роста динамики и масштабов международной торговли и мировой экономики в целом. Перемены в области электронной коммерции весьма динамичны и вынуждают компании к непрерывному мониторингу организационных, экономических и технологических инноваций.

1 Збарская д.г. электронная коммерция: особенности и перспективы (на примере сша и россии)// Экономика и управление народным хозяйством.2018. С.181

2 Digital Economy Compass 2018 [Электронный ресурc]. URL: http://static2.statista.com/ download/pdf/Digital_Economy_Compass_2018.pdf (дата обращения: 6.03.2020) 
${ }^{3}$ Kantar is the world's leading marketing data, insight and consultancy company. [Электронный pecypc]. URL: https://www.kantar.com

${ }^{4}$ Chris Donnelly, Oliver Wright. Accenture Strategy DD Painting Digital Future.2017.

${ }^{5}$ Аналитический обзор "Российский FMCG-ритейл в 2018 г. и прогноз на 2019-2024 гг." [Электронный ресурc]. URL: https://ma-research.ru/research/item/223-rossijskij-fmcg-ritejl-v-2018-g-i-prognozna-2019-2024-gg.html

${ }_{6}^{6}$ Желтенков А. В., Федотова М. А. Развитие систем стратегического управления в промышленных организациях // Вестник Московского государственного областного университета. Серия: Экономика. 2012. № 3. С. 77-81.

${ }^{7}$ Епифанов Е. С., Атаров Н. 3. Основные этапы развития электронного бизнеса // Вопросы региональной экономики. 2016. Т. 28. № 3. С. 106-110.

\title{
E-COMMERCE: GLOBAL AND RUSSIAN TRENDS
}

\author{
(C) 2020 Shvedova Kseniya Sergeevna \\ Student \\ Samara State University of Economics \\ E-mail: ksenya.shvedova@mail.ru
}

Keywords: e-commerce, retail, Russian retail market, world retail market, internet stores, consumers.

This article examines the e-commerce market as part of the retail market and the way forward. The commonalities of the global trend (digitization) stand out and highlight the largest and most influential ecommerce markets. The aim of the study is to identify those trends that will act as modern tools in the development of business of trading enterprises. Analysis of the dynamics of the global e-commerce market, identifying trends in the further development of e-commerce.

УДК 338

Код РИНЦ 06.00.00

\section{СРАВНИТЕЛЬНАЯ ХАРАКТЕРИСТИКА ПЛАТЕЖНЫХ СИСТЕМ VISA, MASTERCARD, "MUP"}

() 2020 Швейкина Марина Юрьевна*

студент

Самарский государственный экономический университет

E-mail: mia.tob6@yandex.ru

Ключевые слова: платежная система, безналичная система оплаты, банковская карта, национальная платежная система.

* Научный руководитель - Шерстенева Тамара Борисовна, кандидат экономических наук, 